International Journal of Engineering, Science and Technology Vol. 2, No. 10, 2010, pp. 79-86

\begin{tabular}{c}
\hline \hline INTERNATIONAL \\
JOURNAL OF \\
ENGINEERING, \\
SCIENCE AND \\
TECHNOLOGY \\
\hline \hline
\end{tabular}

www.ijest-ng.com

\title{
Multi-phase alternative current machine winding design
}

\author{
M. Rizwan Khan ${ }^{1 *}$, Atif Iqbal ${ }^{2}$, SK. Moin Ahmed ${ }^{2}$, S. Moinuddin ${ }^{3}$, Saifullah Payami ${ }^{1}$ \\ ${ }^{1 *}$ Department of Electrical Engineering, Aligarh Muslim University, Aligarh, INDIA \\ ${ }^{2}$ Department of Electrical Engineering, Aligarh Muslim University, Aligarh, INDIA \\ ${ }^{3}$ Department of Electrical Engineering, Sebah University, Sebah, LIBYA \\ *Corresponding Author: e-mail: rizwan.eed@gmail.com, Tel +91-9412545798, Fax.+91-571-2721178
}

\begin{abstract}
In this paper, a generalized formula is proposed for the selection of number of slots required for n-phase alternative current (AC) machine design and the criterion for selecting the starting points of each phases. The analytical model is verified using a four-pole machine with a 36-slot stator. Each coil of the stator winding of this machine is brought out to a patch board that enables the stator to be configured for single-phase to 18-phase excitation. Experimental results of a five-phase induction machine supplied from a static five-phase supply are provided to support the proposed design.
\end{abstract}

Keywords: AC machine, Multi-phase machine, Stator winding, Five-phase

\section{Introduction}

Variable speed electric drives predominately utilize the three-phase machine, however, since the variable speed ac drives require a power electronic converter for their supply (in vast majority of cases an inverter with a dc link), the number of machine phases is essentially unlimited. This has led to an increase in the interest in multiphase ac drive applications, since multiphase machines offer some inherent advantages over their three-phase counterparts. a number of interesting research results have been published over the years and detailed reviews are available in (Jone et al, 2002, Iqbal et al, 2003).

Major advantages of using a multi-phase machine instead of a three-phase machine are detailed in (Jone et al, 2002, Iqbal et al, 2003)and are reduced inrush current, higher torque density, greater efficiency, reduced torque pulsations, greater fault tolerance, and reduction in the required rating per inverter leg (and therefore simpler and more reliable power conditioning equipment). Additionally, noise characteristics of the drive improve as well. The applications of multi-phase motor are rail wagon tippler, 'more electric' aircraft, electric ship propulsion, traction and EV/HEVs. The detailed design of electric machines is given in (Sawhney, 2002, Say, 2003). The special design of stator core, rotor core, stator teeth, rotor teeth, stator winding, rotor winding, air-gap flux, machine enclosure, machine ventilation, machine efficiency optimization etc is explained in (Ohtsuka et al, 1996, Bianchi et al, 2006, Zhang et al, 2007, Granner, 2008, Choi et al, 2007, Ting et al, 2007).

\section{N-phase AC Machine Design}

The paper presents a generalized relationship for determining the number of slots to be used and their starting point. Specific example of three, four and five-phase machines are taken up first followed by presentation of generalized design for n-phase machine.

(A) Three-phase AC machine

(i) Three-phase two pole ac machine

For a three-phase ac machine the phase angle between any two consecutive phases is given as: $\phi=\frac{360^{\circ}}{3}($ electrical $)=120^{\circ}($ electrical $)=120^{\circ}($ mechanical $)$; for two pole ac machine. 
For example, the number of slots required and their allocation for three-phase two pole ac machine are given in Table 1.

Table 1: Three-phase two pole machine stator slots allocation

\begin{tabular}{|c|c|c|c|c|c|c|}
\hline \multicolumn{3}{|c|}{ POLE-1 } & \multicolumn{3}{c|}{ POLE-2 } & $\begin{array}{c}\text { NO. } \\
\text { OF } \\
\text { ALOTS }\end{array}$ \\
\hline 1 & C & B & A & C & B & 6 \\
\hline 2 & 1 & 1 & 1 & 1 & 1 & 9 \\
\hline 2 & 2 & 2 & 2 & 2 & 2 & 12 \\
\hline 3 & 2 & 3 & 2 & 3 & 2 & 15 \\
\hline 3 & 3 & 3 & 3 & 3 & 3 & 18 \\
\hline 4 & 3 & 4 & 3 & 4 & 3 & 21 \\
\hline 4 & 4 & 4 & 4 & 4 & 4 & 24 \\
\hline$\cdots$ & $\cdots$ & $\cdots$ & $\cdots$ & $\cdots$ & $\cdots$ & $\cdots$ \\
\hline
\end{tabular}

Here A, B, C represent three phases of machine. All phases (A, B \& C) are under each pole as shown in the "Table 1,". The last column lists the no. of slots required to wind a 3-phase, 2-pole machine. The minimum no. of slots required to design such machine should be 6 . The increment in the slots should be in the step of 3 . There is no limit imposed on the maximum no. of slot, however the optimum design require a suitable no. There are some constraints in the selection of stator slots and are

(i) Number of slots per phase should be same for each phase.

(ii) Minimum number of slots $=\mathrm{n} * \mathrm{P}$, where $\mathrm{n}$ is the no. of phases of a machine and $\mathrm{P}$ is the no. of poles of a machine.

(iii) For symmetrical winding, the slot/pole should be an integer and for asymmetrical winding, the slot/pole should be a noninteger.

In general, the number of slots required are $[6+3 K]=3 *[2+K]$, where $K=0,1,2,3, \ldots \ldots \ldots$.

$$
\text { Therefore per slot angle }=\frac{360^{\circ}}{3 *[2+K]}=\frac{120^{\circ}}{[2+K]}(\text { mech })
$$

And required phase angle between any two consecutive phases in terms of slots $=120^{\circ} /$ slot.angle $=[2+K]$ slots .

This suggest that if phase-A starts from slot no. 1 then phase-B will starts from $[2+K]$ th slot and phase-C from $2 *[2+K]$ th slot.

(ii) Three-phase four pole ac machine

For a three-phase ac machine the phase angle between any two consecutive phases is given as:

$\phi=\frac{360^{\circ}}{3}($ electrical $)=120^{\circ}($ electrical $)=60^{\circ}($ mechanical $)$; for four pole ac machine.

Similarly, the number of slots and winding disposition required for three-phase four pole ac machines can be found.

In general, the number of slots required are $6 *[2+K]$, where $K=0,1,2,3, \ldots \ldots \ldots$.

$$
\text { Therefore per slot angle }=\frac{360^{\circ}}{6 *[2+K]}=\frac{60^{\circ}}{[2+K]}(\text { mech })
$$

And required phase angle between two consecutive phases in terms of slots $=60^{\circ} /$ slot.angle $=[2+K]$ slots .

If phase-A starts from slot no. 1 then phase-B will starts from $[2+K]$ th slot and phase-C from $2 *[2+K]$ th slot. In general for $\mathrm{P}$ number of poles three-phase ac machine, the number of slots required are:

$$
S=\frac{3}{2} \cdot P \cdot[2+K] \text { slots }
$$

where $\mathrm{K}=0,1,2,3, \ldots \ldots$

\section{(B) Four-phase AC machine}


(i) Four -phase two pole ac machine

For a Four-phase ac machine the phase angle between any two consecutive phases is given as: $\phi=\frac{360^{\circ}}{4}($ electrical $)=90^{\circ}($ electrical $)=90^{\circ}($ mechanical $)$; for two pole ac machine.

In general, the number of slots required are $4 *[2+K]$, where $K=0,1,2,3, \ldots \ldots \ldots$.

$$
\text { Therefore per slot angle }=\frac{360^{\circ}}{4 *[2+K]}=\frac{90^{\circ}}{[2+K]}(\text { mech })
$$

And required phase angle between any two consecutive phases in terms of slots $=90^{\circ} /$ slot.angle $=[2+K]$ slots .

If phase-A starts from slot no. 1 then phase-B will starts from $[2+K]$ th slot, phase-C from $2 *[2+K]$ th slot and phase-D from $3 *[2+K]$ th slot.

(ii) Four -phase four pole ac machine

For a Four-phase ac machine the phase angle between any two consecutive phases is given as:

$\phi=\frac{360^{\circ}}{4}($ electrical $)=90^{\circ}($ electrical $)=45^{\circ}($ mechanical $)$; for four pole ac machine.

In general, the number of slots required are $8 *[2+K]$ where $K=0,1,2,3, \ldots \ldots \ldots$

$$
\text { Therefore per slot angle }=\frac{360^{\circ}}{8 *[2+K]}=\frac{45^{\circ}}{[2+K]}(\text { mech })
$$

And required phase angle between any two consecutive phases in terms of slots $=45^{\circ} /$ slot.angle $=[2+K]$ slots .

If phase-A starts from slot no. 1 then phase-B will starts from $[2+K]$ th slot, phase-C from $2 *[2+K]$ th slot and phase-D will starts from $3 *[2+K]$ th slot .

In general for P number of poles four-phase c machine, the number of slots required are:

$$
S=\frac{4}{2} \cdot P \cdot[2+K] \text { slots } \ldots \ldots
$$

where $K=0,1,2,3, \ldots \ldots \ldots \ldots$

\section{(C) Five-phase AC machine}

(i) Five -phase two pole ac machine

Five -phase ac machine the phase angle between any two consecutive phases is given as:

$\phi=\frac{360^{\circ}}{5}($ electrical $)=72^{\circ}($ electrical $)=72^{\circ}($ mechanical $)$; for two pole ac machine.

In general, the number of slots required are $5 *[2+K]$ where $K=0,1,2,3, \ldots \ldots \ldots \ldots$

$$
\text { Therefore per slot angle }=\frac{360^{\circ}}{5 *[2+K]}=\frac{72^{\circ}}{[2+K]}(\text { mech })
$$

And required phase angle between two consecutive phases in terms of slots $=72^{\circ} /$ slot.angle $=[2+K]$ slots .

If phase-A starts from slot no. 1 then phase-B will starts from $[2+K]$ th slot, phase-C from $2 *[2+K]$ th slot, phase-D from $3 *[2+K]$ and phase-E from $4 *[2+K]$ th slot.

(ii) Five -phase four pole ac machine

For a Five -phase ac machine the phase angle between any two consecutive phases is given as:

$$
\phi=\frac{360^{\circ}}{5}(\text { electrical })=72^{\circ}(\text { electrical })=36^{\circ}(\text { mechanical }) \text {; for four pole ac machine. }
$$

In general, the number of slots required are $[20+10 \mathrm{~K}]=10 *[2+\mathrm{K}]$ where $\mathrm{K}=0,1,2,3, \ldots \ldots \ldots \ldots$ 


$$
\text { Therefore per slot angle }=\frac{360^{\circ}}{10 *[2+K]}=\frac{36^{\circ}}{[2+K]}(\text { mech })
$$

And required phase angle between any two consecutive phases in terms of slots $=36^{\circ} /$ slot .angle $=[2+K]$ slots .

If phase-A starts from slot no. 1 then phase-B will starts from $[2+\mathrm{K}]$ th slot, phase-C from $2 *[2+\mathrm{K}]$ th slot, phase-D from $3 *[2+\mathrm{K}]$ th and phase-E will starts from $4 *[2+\mathrm{K}]$ th slot .

In general for $\mathrm{P}$ number of poles five-phase ac machine, the number of slots required are:

$$
S=\frac{5}{2} \cdot P \cdot[2+K] \text { slots } \ldots \ldots \ldots
$$

where $K=0,1,2,3, \ldots \ldots \ldots \ldots$

\section{Generalized Design}

From the above discussion it can be concluded that

For 3-Phase ac machine no. of slots is: $S=\frac{3}{2} \cdot P \cdot[2+K]$ slots

For 4-Phase ac machine no. of slots is: $S=\frac{4}{2} \cdot P \cdot[2+K]$ slots

For 5-Phase ac machine no. of slots is: $S=\frac{5}{2} \cdot P \cdot[2+K]$ slots

Therefore following the same trend, in general for n-phase ac machine, the no. of slots required is

$$
S=\frac{n}{2} \cdot P \cdot[2+K] \text { slots } \ldots . .
$$

where $S=$ no. of machine slots required

$n=$ no. of machine phases

$P=$ no. of machine poles

and $\quad K=0,1,2,3, \ldots \ldots \ldots .$.

And starting points (slots) of the different phases are given as:

$$
1+\gamma[2+K] \ldots
$$

In general $\gamma=(n-1)$ for $n$th phase.

Also for symmetrical ac winding: $K=0,2,4, \ldots \ldots \ldots$

And for asymmetrical ac winding: $K=1,3,5, \ldots \ldots$.

\section{Experimental Results}

A five-phase induction motor of 30 slots, four pole and asymmetrical winding has been designed using the derived formula. The coil-pitch is fixed 6-slots. The experimental results are obtained by direct fed supply from a special connection scheme of transformer termed as AMR (Atif-Moinuddin-Rizwan) connection (Iqbal et al., 2010). The developed transformer connection scheme transforms available three-phase supply system to a five-phase supply system. A patent has been sought for this product. The slot selection is shown in Figure 1, and winding distribution of each phase is shown in Figure 2. The experimental results are illustrated in Figure 3 to Figure 10. Figure 1 shows a complete distribution of windings, starting points and finishing points. The number of slots occupied per pole pair is 15. This is a special way to show the phase windings of a multi-phase machine. Figure 2(a) to Figure 2(b) shows each phase winding in different poles. 


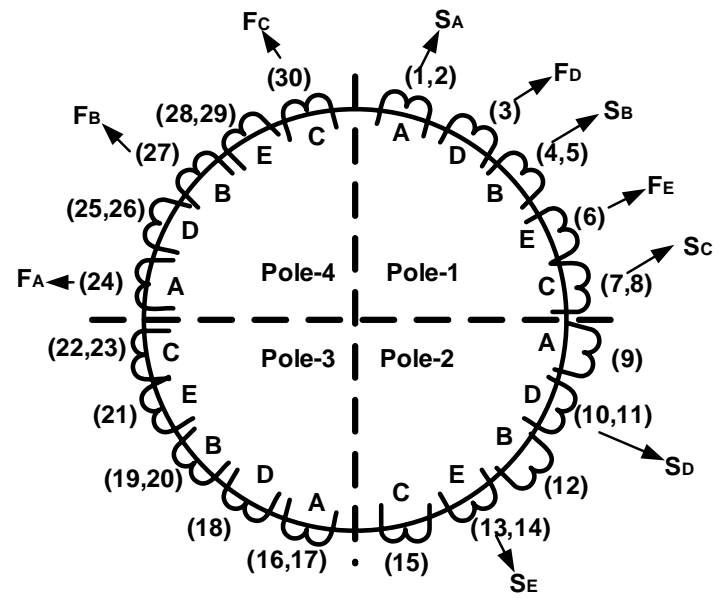

Figure 1: Slots distribution, phase sequence, starting and finishing points of different phases.

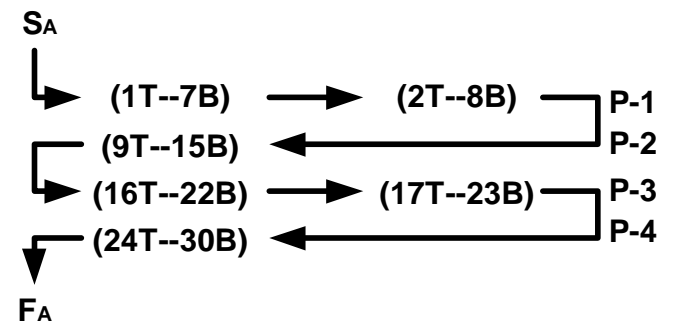

(a) Phase-A winding arrangements

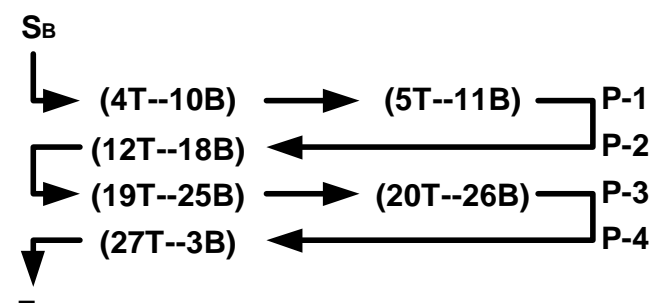

FB

(b) Phase-B winding arrangements

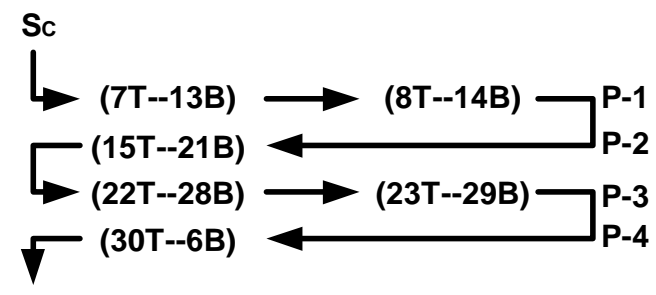

Fc

(c) Phase-C winding arrangements

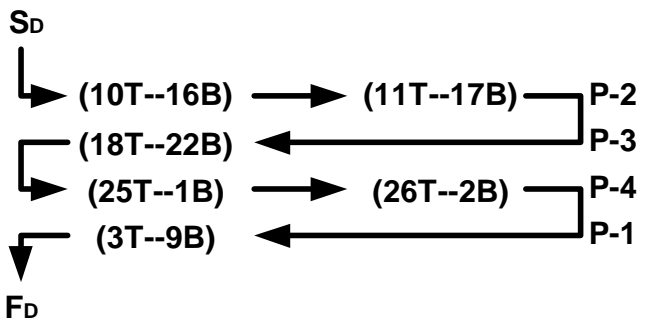

(d) Phase-D winding arrangements

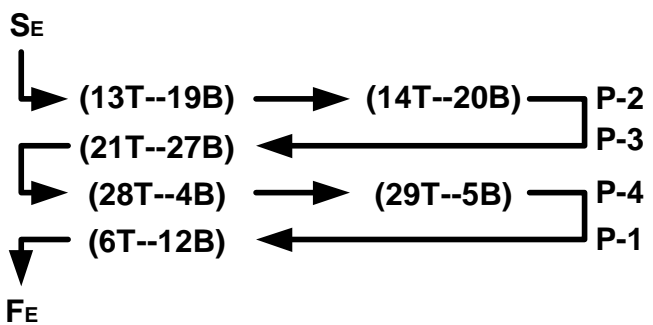

(e) Phase-E winding arrangements

Figure 2: Phase A to E winding arrangement under different poles.

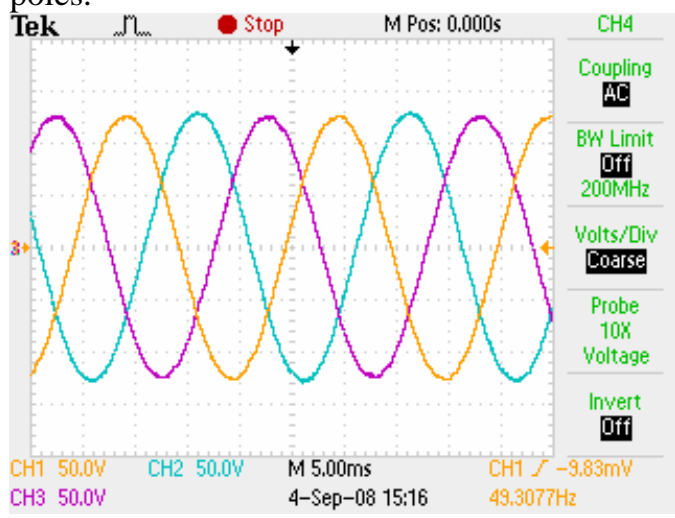

Figure 3: Transformer input phase voltages $V a, V b, V c$ at no-load.

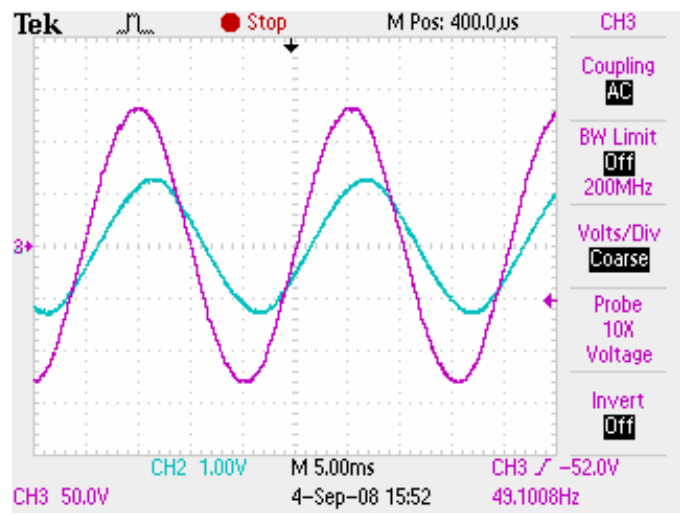

Figure 4: Five-phase motor input phase voltage $V_{a}$ and current $I_{a}$ at load. 


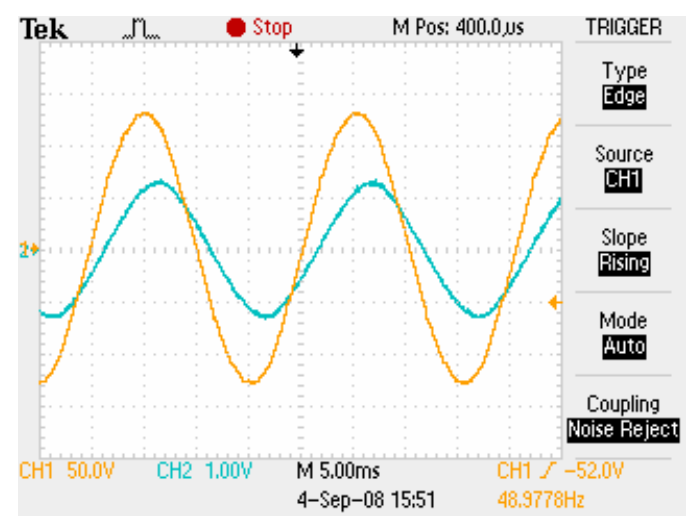

Figure 5: Five-phase motor input phase voltage $V_{b}$ and current $I_{b}$ at load.

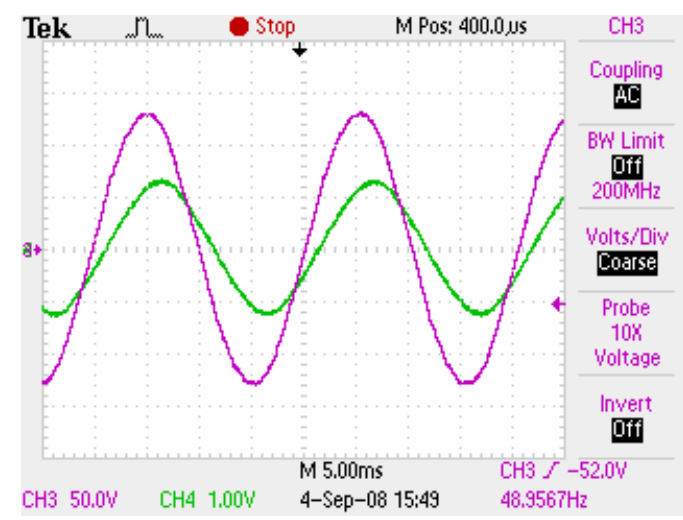

Figure 6: Five-phase motor input phase voltage $V_{c}$ and current $I_{c}$ at load.

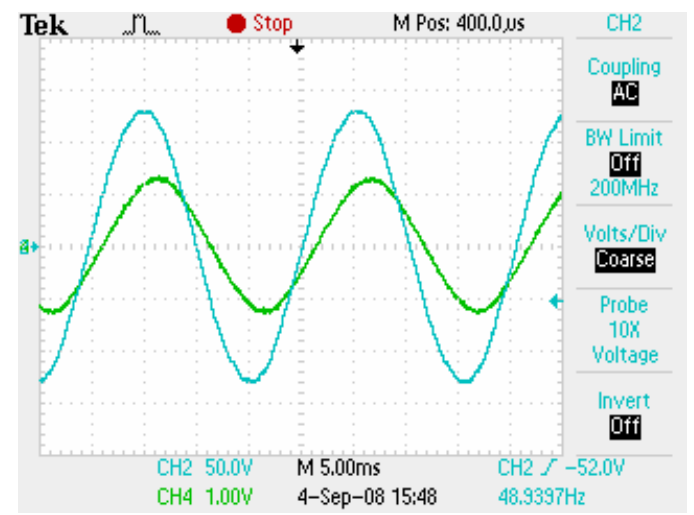

Figure 7: Five-phase motor input phase voltage $V d$ and current Id at load.

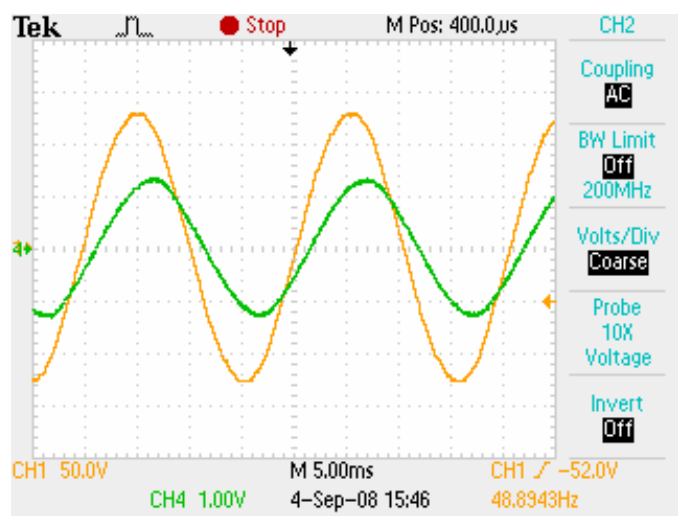

Figure 8: Five-phase motor input phase voltage $V_{e}$ and current $I_{e}$ at load.

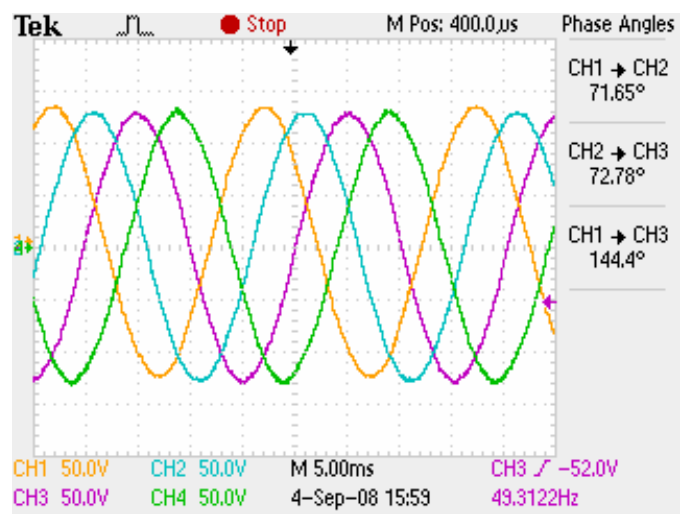

Figure 9: Five-phase motor input phase voltages $V_{a}, V_{b}, V_{c}$, and $V_{d}$ at load.

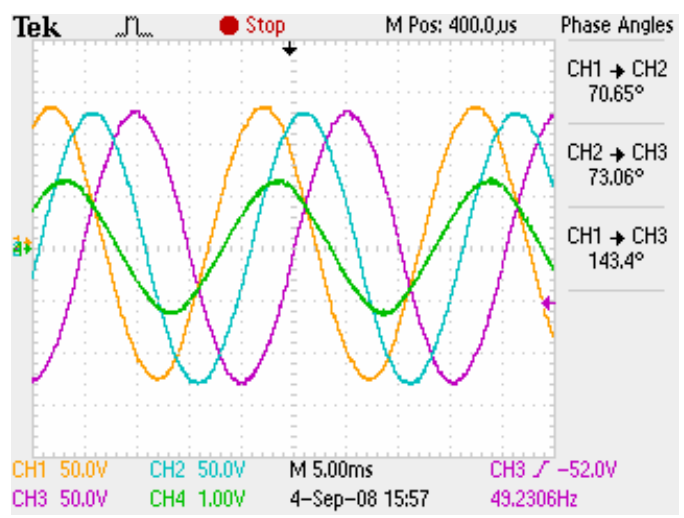

Figure 10: Five-phase motor input phase voltages $V_{a}, V_{b}, V_{c}$ and current $I_{a}$ at load. 


\section{Discussion}

At no-load, the voltage input to the 3-to-5 phase transformer (AMR-connection) is kept at 90 volt. The no-load speed of fivephase motor is $1440 \mathrm{rpm}$. At load, input voltage to transformer is 90 volt. An eddy current load is connected to the five-phase motor through shaft coupling for loading purpose. The eddy current loading (armature) voltage is 10 volt, load current (per phase) is $0.85 \mathrm{amp}$ and motor speed is $1412 \mathrm{rpm}$. Figure 3 show the three-phase transformer input phase voltages $V_{a}, V_{b}, V_{c}$ at no-load. Figure 4 to Figure 8 show Five-phase motor input phase voltages $V_{a}, V_{b}, V_{c}, V_{d}, V_{e}$ and currents $I_{a}, I_{b}, I_{c}, I_{d}, I_{e}$ at load, respectively. Figure 9 show the five-phase motor input phase voltages $V_{a}, V_{b}, V_{c}$, and $V_{d}$ and Figure 10 show the five-phase motor input phase voltages $V_{a}, V_{b}, V_{c}$ and current $I_{a}$ at load conditions. All the presented results are typical to any five-phase induction machine and hence validating our design. In experimental results, the voltages and currents input to the transformer and input to the motor are sinusoidal. The currents having no harmonics, the reason for this is that a short pitch winding in stator has been used. The results obtained with five-phase induction machine are satisfactorily in terms of phase difference between any two phases which is $72^{\circ}$ (Electrical) and the phase relationship between phase voltage and phase current.

\section{Conclusions}

This paper presents an approach for the selection of number of slots for n-phase ac machine and their selection of starting and finishing points. The developed technique can be used for any number of phases of an ac machine. The slots distribution and winding distribution are also presented for 3-phase, 4-phase and 5-phase. Also experimental results of a five-phase induction machine are presented for the verification of the findings.

\section{Acknowledgement}

The work reported is funded by Council of Scientific and Industrial Research (CSIR), India, File No. 22(0462)09/EMR-II, 2009.

\section{References}

Bianchi, N., Bolognani, S. and Frare, P. 2006. Design criteria for high efficiency SPM synchronous motors. IEEE Trans On Energy Conversion, Vol. 21, No.2, June, pp. 396-404.

Choi, Y. C. and Lee, J. H. 2007. Rotor and stator design on torque ripple reduction for a synchronous reluctance motor with a concentrated winding using RSM. Int. Conf. Electrical Machines and Systems, 2007, Oct. 8-11, Seoul, Korea, pp. 1216-1221.

Granner, C. 2008. Report about acoustic effects of converter fed induction motors with novel stator design. CCECE, May, 5-7, Niagara falls, Canada, pp. 283-288.

Iqbal, A., Vukosavi, S.N. and Levi, E. 2003. Vector control of a five-phase induction motor drive. Proc. $38^{\text {th }}$ UPEC, Thessoloniki, Greece, 2003, CD-ROM paper No. EMDII, pp.57-60.

Iqbal, A., Moinoddin, S., Khan, M.R., Moin, SK. A. 2010. A novel three to five-phase transformation using special transformer connection., IEEE Trans.on Power Delivery, Vol. 25, No. 3, pp. 1637-1644.

Jones, M. and Levi, E. 2002. A literature survey of state-of-the-art in multiphase ac drives. Proc. $37^{\text {th }}$ Int. Universities Power Eng. Conf. UPEC, Stafford, UK, pp. 505-510.

Ohtsuka, H., Tsuchiya, J., Shimiza, T. and Kimura, G. 1996. Stator design of revolvable surface motor. IEEE Int. conf. on Ind. Technology, pp. 634-637.

Sawhney, A.K. 2001. Electrical Machine Design. Dhanpat Rai \& Co.(P) Ltd.-Delhi.

Say, M.G. 1958. The Performance and Design of Alternating Current Machines. ELBS Publication, London.

Ting, Y., Chen, L. C. , Li, C.C. and Huang, J.L. 2007. Traveling-wave piezoelectric linear motor Part-I: The stator Design. IEEE Trans. On Ultrasonics, Ferroelectrics and Frequency control,, Vol. 4, April, pp. 847-853.

Zhang, J. Cheng, M. and Chen, Z. 2007. A novel stator interior permanent magnet generator for direct-drive wind turbines. Int. Conf. Electrical Machines and Systems, Oct. 8-11, Seoul, Korea, pp. 723-728.

\section{Biographical notes}

Dr. M. Rizwan Khan received his B.Sc. Engineering, M.Tech. (Electrical) and Ph.D. degrees in 1998, 2001 and 2008 respectively, from the Aligarh Muslim University, Aligarh, India. He is an Asstt. Professor in the Department of Electrical Engineering, Aligarh Muslim University, Aligarh since 2001. His principal area of research interest is Power Electronics, Artificial Intelligence and Multi-phase motor drives.

Dr. Atif Iqbal received his B.Sc. and M.Sc. Engineering (Electrical) degrees in 1991 and 1996, respectively, from the Aligarh Muslim University, Aligarh, India and PhD in 2005 from Liverpool John Moores University, Liverpool, UK. He has been employed as Lecturer in the Department of Electrical Engineering, Aligarh Muslim University, Aligarh since 1991 and is currently working as an Associate Professor in the same university. He is recipient of Maulana Tufail Ahmad Gold Medal for standing first at B.Sc. Engg. Exams in 1991, AMU and research fellowship from EPSRC,UK for pursuing Ph.D. studies. His principal area of research interest is Power Electronics and Multi-phase machine drives. Presently he is working with Texas A\&M University at Qatar. 
Sk. Moin Ahmed was born in Hooghly, West Bengal, India, in 1983. He received the B.Tech and M.Tech. degrees from Aligarh Muslim University (AMU), Aligarh, India, in 2006 and 2008, respectively, where he is currently pursuing the Ph.D. degree. He is also pursuing a research assignment at Texas A\&M University at Qatar. His principal areas of research are modeling, simulation, and control of multi-phase power electronic converters and fault diagnosis using Artificial intelligence. Mr. Ahmed was a Gold Medalist in earning the M.Tech degree. He is a recipient of Toronto Fellowship, funded by AMU.

Shaikh Moinuddin received his B.E. and M.Tech (Electrical) degrees in 1996 and 1999, respectively, from the Aligarh Muslim University, Aligarh, India. He has completed his $\mathrm{PhD}$ in 2009 on multi-phase inverter modeling and control from AMU. He is recipient of University Gold Medals for standing first in Electrical branch and in all branches of Engineering in 1996 B.E. exams. He has served Indian Air Force from 1971 to 1987. He is employed in the University Polytechnic, Aligarh Muslim University since 1987 where he is currently working as a Lecturer. His principal areas of research interest are Power Electronics and Electric Drives. He is currently on academic assignment, Sebha University, Lybia.

Saifullah Payami received his B.Tech (Electrical) and M.Tech (Power System \& Drives) in 2007 and 2010, respectively, from Aligarh Muslim University, Aligarh, India. Currently he is working as Junior Research Fellow in a CSIR funded project at Department of Electrical Engineering, AMU. His area of research interest is Power Electronics, Multi-phase Machine Drives and Renewable Energy Systems

Received August 2010

Accepted October 2010

Final acceptance in revised form November 2010 